\title{
Thermodynamic Studies on the Glass Transition and the Glassy State of Polymers. III. Poly $(\alpha$-methylstyrene)
}

\author{
Shoji Ichihara*, Akihiko Komatsu**, and Toshio Hata \\ Department of Polymer Chemistry, Tokyo Institute of \\ Technology, Tokyo, Japan
}

(Received March 8, 1971)

\begin{abstract}
For two series of glasses of poly $(\alpha$-methylstyrene), the densified glasses formed under various high pressures at the ordinary cooling rates $\left(1^{\circ} \mathrm{C} / \mathrm{min}\right)$ and slowly cooled glasses formed at various slow rates of cooling under atmospheric pressure, heats of solution, and specific heats were measured. In the glass-forming processes, dilatometric measurements were also made. The results differ in many points from those of polystyrene reported in previous papers. For example, the glass transition temperature $T_{\mathrm{g}}$, the specific volume $V_{\mathrm{S}}$ at $30^{\circ} \mathrm{C}$, and heat of solution or the enthalpy $H$ of the densified glass do not vary linearly with the glass-forming pressure $P$. Consequently $\left(\partial T_{\mathrm{g}} / \partial P\right)$ and $(\partial H / \partial P)$ decrease and $\beta^{\prime}=-\left(\partial \ln V_{\mathrm{s}} / \partial P\right)$ increase with increase of pressure. However, the theoretical relations about $\left(\partial T_{\mathrm{g}} / \partial P\right)$ derived by Nose are shown to be valid in these cases too, at least below the pressure of $450 \mathrm{~kg} / \mathrm{cm}^{2}$. The criterion of the iso-configurational entropy or energy for $T_{\mathrm{g}}$ is established only under near atmospheric pressure. For the slowly cooled glasses, the relations $\Delta H=\Delta C_{p} \Delta T_{\mathrm{g}}$ and $\Delta V=V \Delta \alpha \Delta T_{\mathrm{g}}$ are derived and confirmed. The small value of $\Delta C_{p}$ intra calculated is discussed in comparison with the value for polystyrene, where $\Delta C_{p}{ }^{\text {intra }}$ is the specific heat change at $T_{\mathrm{g}}$ associated with intramolecular degrees of freedom.
\end{abstract}

KEY WORDS Poly $(\alpha$-methylstyrene $)$ / Glass Transition / Glassy State /

Pressure Dependence/Configurational Entropy/Specific Heat /

Enthalpy / Specific Volume / Densified Glass / Annealed Glass /

In previous papers, ${ }^{1,2}$ we have shown for for polystyrene that the glass transition temperature, $T_{\mathrm{g}}$, of the densified glass which was formed under elevated pressure obeys the relations

$$
\left(\frac{\partial T_{\mathrm{g}}}{\partial P}\right)=\frac{T V \Delta \alpha}{\Delta C_{p}}<\frac{\Delta \beta}{\Delta \alpha},
$$

where $\Delta \alpha, \Delta \beta$, and $\Delta C_{p}$ are the differences of thermal expansion coefficients, compressibilities, and specific heats between the liquid and glassy states and $P, V$, and $T$ are pressure, volume, and temperature respectively. The enthalpy remains constant for the glasses formed under different pressures, notwithstanding the considerable difference of $T_{\mathrm{g}}$ and specific volume. Corresponding to this fact, the behaviors of specific

* Present adress: Plastics Research Laboratory, Mitsubishi Petrochemical Co., Yokkaichi, Mie, Japan.

** Present adress: Showa Denko Co., Tamagawa, Ohta-ku, Tokyo, Japan. heats against temperature are also the same as each other. All these facts have been explained by the concept of the iso-configurational energy or entropy at $T_{\mathrm{g}}$ as pointed out by Nose. ${ }^{3}$

On the other hand, enthalpies of the slowly cooled glasses which were formed by cooling at different rates decrease with the decrease of $T_{\mathrm{g}}$. The decrease of the enthalpy has been shown to be equal to $\Delta C_{p} \times \Delta T_{\mathrm{g}}$ both experimentally and theoretically.

In this paper we apply the same analysis to the glasses of $\operatorname{poly}(\alpha$-methylstyrene) with interest in the small difference of the molecular structure and consequently of inter- and intra-segmental interactions from polystyrene.

\section{EXPERIMENTAL}

\section{Samples}

Poly $(\alpha$-methylstyrene) (P $\alpha$ MS) was prepared by anionic polymerization with sodium naphthalene 
as a catalyst. The obtained polymer was purified by repeated reprecipitations with benzene and $n$-hexane. After sufficient drying (for 3 day under atomospheric conditions, for a week under vacuum, and for 3 day at $180^{\circ} \mathrm{C}$ under vacuum), the powders were heat-molded at $200-210^{\circ} \mathrm{C}$ to a block sample.

Two series of glasses were prepared from this block sample; the densified glasses and the slowly cooled glasses. The former were formed under the pressures of $1 \mathrm{~atm}, 150,300,450$, and $600 \mathrm{~kg} / \mathrm{cm}^{2}$ with the cooling rate of $1{ }^{\circ} \mathrm{C} / 3$ min and the latter were glasssified with the cooling rates of $1^{\circ} \mathrm{C}$ per $3 \mathrm{~min}, 1,3$, and $10 \mathrm{hr}$, and 1 day under atmospheric pressure.

\section{Measurements}

In the process of glass-formation, the dilatometric measurements were done at the same time. Densities, heats of solution in benzene at $30^{\circ} \mathrm{C}$ and speciflc heats were measured for each glass. The methods and apparatuses were the same as in previous papers. In this study DSC measurements were made under the conditions of scanning speed $16^{\circ} \mathrm{C} / \mathrm{min}$, sensitivity $4 \mathrm{mcal} / \mathrm{sec}$, and scanning interval $110^{\circ} \mathrm{C}$. The standard deviations of the measured values were $0.0002 \mathrm{cc} / \mathrm{g}$ for specific volume, $0.6 \%$ for heat of solution, and $0.005 \mathrm{calg}^{-1} \mathrm{~K}^{-1}$ or $1.1 \%$ for specific heat.

\section{RESULTS}

\section{Results from $P-V-T$ relations}

In Figure 1 the glass transition temperatures $T_{\mathrm{g}}$ of slowly cooled glasses are shown against

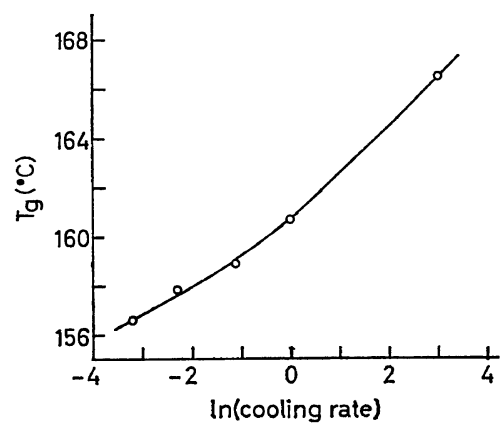

Figure 1. $T_{\mathrm{g}}$ of P $\alpha \mathrm{MS}$ under $1 \mathrm{~atm}$ plotted against $\ln \left(\right.$ cooling rate in ${ }^{\circ} \mathrm{C} / \mathrm{hr}$ ).

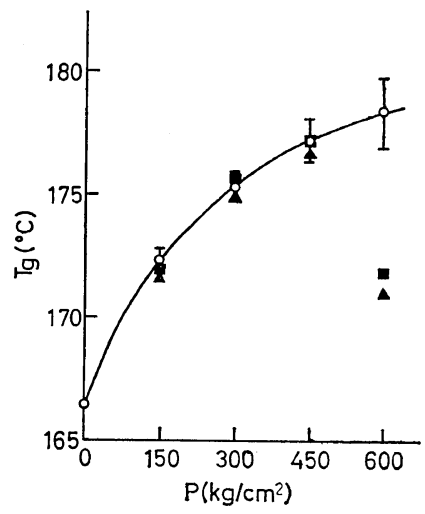

Figure 2. $T_{\mathrm{g}}$ of $\mathrm{P} \alpha \mathrm{MS}$ cooled at $1^{\circ} \mathrm{C} / 3$ min plotted against applied pressure: $\bigcirc$, observed; $\Delta$, calculated by eq $2 ; \mathbf{E}$, calculated by eq 4 .

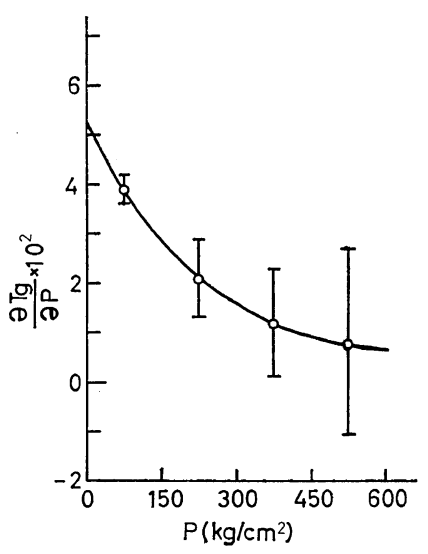

Figure 3. $\left(\partial T_{\mathrm{g}} / \partial P\right)$ plotted against mean values of pressure.

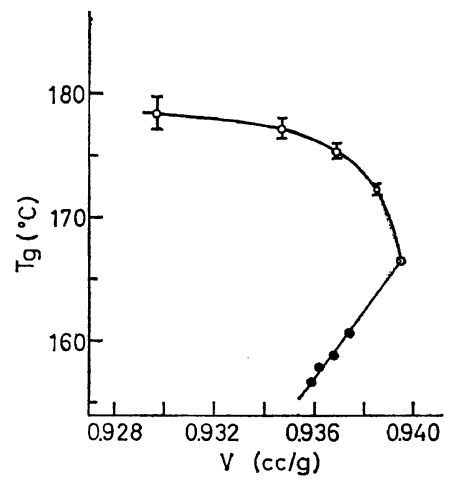

Figure 4. Specific volumes $V$ of $\mathrm{P} \alpha \mathrm{MS}$ at $30^{\circ} \mathrm{C}$ plotted against $T_{\mathrm{g}}$ in the processes of glass-formation; 0 , slowly cooled glass; $\bigcirc$, densified glass; $\odot$, glass cooled at $1^{\circ} \mathrm{C} / 3 \mathrm{~min}$ under $1 \mathrm{~atm}$. 
logarithmic cooling rates and in Figure 2 those of densified glasses are shown against pressures. In the present study for $\mathrm{P} \alpha \mathrm{MS}$, the relation between $T_{\mathrm{g}}$ and pressure is not linear, being different from that for polystyrene (PS). Solid triangles and squares in Figure 2 are the calculated values in the next section. Figure 3 shows $\left(\partial T_{\mathrm{g}} / \partial P\right)$ against pressure. Here $\left(\partial T_{\mathrm{g}} / \partial P\right)$ was approximated by $\Delta T_{\mathrm{g}} / \Delta P=\left[T_{\mathrm{g}}\left(P_{2}\right)-T_{\mathrm{g}}\left(P_{1}\right)\right] /$ $\left(P_{2}-P_{1}\right)$, and the pressure was the mean value, $\left(P_{1}+P_{2}\right) / 2$.

Figure 4 shows the relations of $T_{\mathrm{g}}$ to the specific volumes at $30^{\circ} \mathrm{C}$ of the densified glasses and slowly cooled glasses. In the case of PS, those of the densified glasses showed the linear relation up to $600 \mathrm{~kg} / \mathrm{cm}^{2}$ but here did not do so. The decrease of the specific volumes of the slowly cooled glasses is nearly equal to $V \Delta \alpha T_{\text {g }}$ (see the next section).

In Figure $5 \mathrm{a}$ the specific volumes of the densified glass and in Figure $5 b \quad \beta^{\prime}=-(\partial \ln V / \partial P) \cong$ $-(\Delta \ln V / \Delta P)$ are shown against the glass-forming pressures. In the latter figure, the pressure of the abscissa is taken as a mean value of the pressures, between which $\beta^{\prime}$ is estimated.

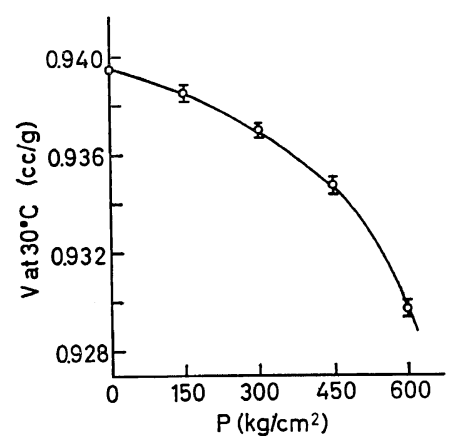

Figure 5a. Specific volumes of densified glasses at $30^{\circ} \mathrm{C}$ plotted against the pressure applied in the processes of glass-formation.

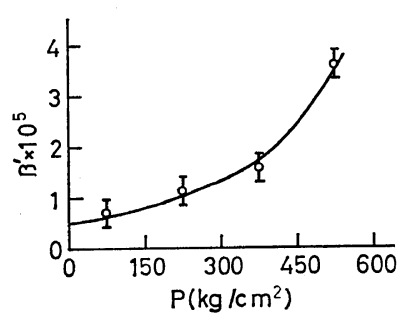

Figure 5b. Pressure dependence of $\beta^{\prime}$.

\section{Results of thermal measurements}

The heats of solution, $Q$, at $30^{\circ} \mathrm{C}$ of two series of glasses vs. $T_{\mathrm{g}}$ are shown in Figure 6. Here again the constancy of $Q$ of the densified glasses is not found. In Figure $7 \mathrm{a} Q$ and in Figure $7 \mathrm{~b}(\partial H / \Delta P) \cong(\Delta H / \Delta P)$ are shown against the glassforming pressures. In the case of PS $(\partial H / \partial P)$ is zero up to $600 \mathrm{~kg} / \mathrm{cm}^{2}$, corresponding to the

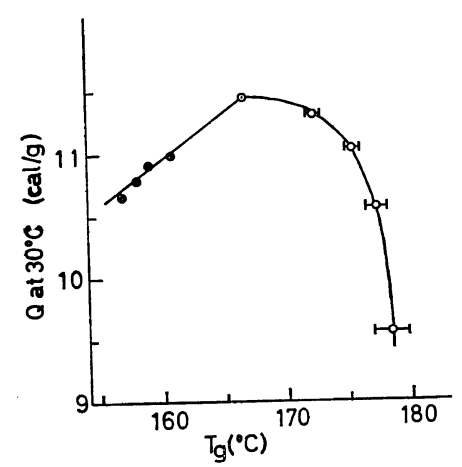

Figure 6. Heats of solution $Q$ of $\mathrm{P} \alpha \mathrm{MS}$ to benzene at $30^{\circ} \mathrm{C}$ plotted against $T_{\mathrm{g}}$ in the processes of glass-formation. $\bullet$, slowly cooled glass; $\bigcirc$, $\odot$, glass cooled at $1^{\circ} \mathrm{C} / 3$ min under $1 \mathrm{~atm}$.

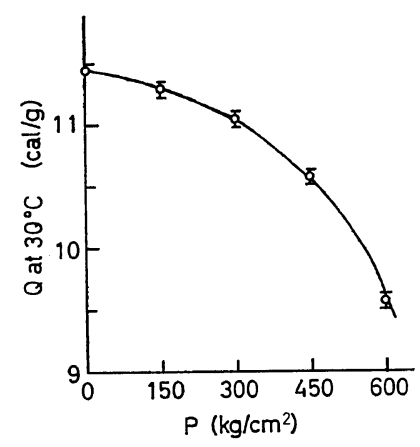

Figure 7a. Heats of solution of densified P $\alpha$ MS to benzene at $30^{\circ} \mathrm{C}$ plotted against the pressure applied in the processes of glass-formation.

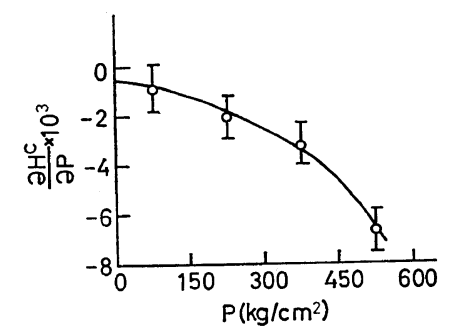

Figure 7b. Pressure dependence of $(\partial H / \partial P)$. 
Thermodynamic Studies on Glass Transition and Glassy State of Polymers. III.

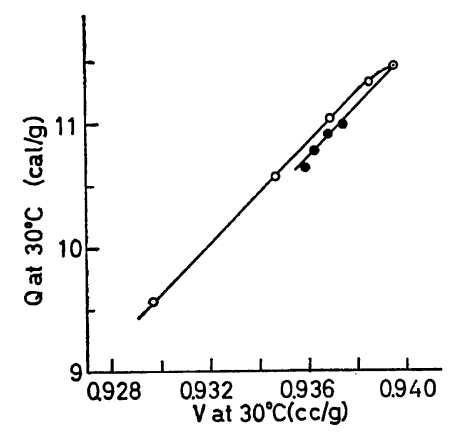

Figure 8. Specific volumes of densified glasses plotted against heats of solution to benzene at $30^{\circ} \mathrm{C}$ : slowly cooled glass; $\bigcirc$, densified glass; $\odot$, glass cooled at $1^{\circ} \mathrm{C} / 3 \mathrm{~min}$ under $1 \mathrm{~atm}$.

constancy of the heat of solution. Figure 8 illustrates the relations of the heats of solution to the specific volumes at $30^{\circ} \mathrm{C}$ for both series of glasses.

Specific heats, $C_{p}$, vs. temperature are shown in Figure 9 for the slowly cooled glasses and in Figure 10 for the densified glasses. The slower the rate of cooling, the higher is the peak of specific heat. This behavior is quite similar to that found in PS $^{2}$ and the isothermally annealed glasses ${ }^{4}$ of PS. On the other hand,

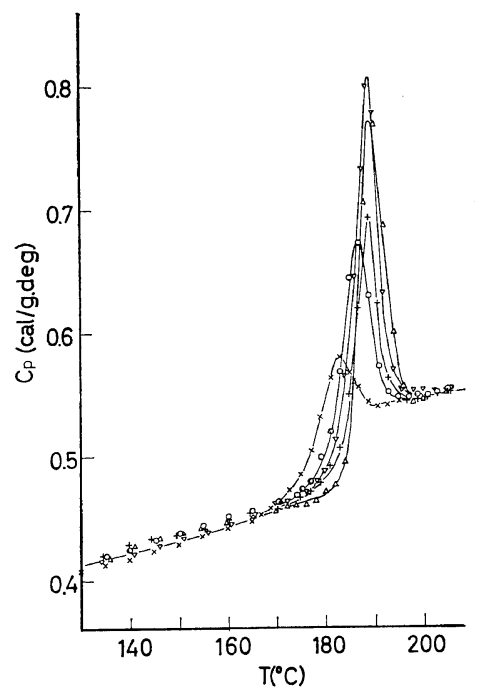

Figure 9. Specific heats of slowly cooled P $\alpha$ MS measured with DSC using the heating rate of $16^{\circ} \mathrm{C} / \mathrm{min}$, cooled beforehand under $1 \mathrm{~atm}$ at $1^{\circ} \mathrm{C} /$ $3 \mathrm{~min},(\times), 1^{\circ} \mathrm{C} / \mathrm{hr}(\bigcirc), 1^{\circ} \mathrm{C} / 3 \mathrm{hr}(+), 1^{\circ} \mathrm{C} / 10 \mathrm{hr}(\triangle)$ and $1^{\circ} \mathrm{C} /$ day $(\nabla)$.

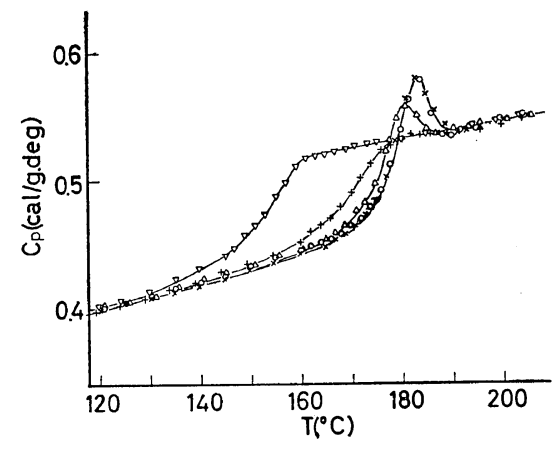

Figure 10. Specific heats of densified $\mathrm{P} \alpha \mathrm{MS}$ measured with DSC using the heating rate of $16^{\circ} \mathrm{C} / \mathrm{min}$, cooled beforehand at $1^{\circ} \mathrm{C} / 3$ min under $1 \mathrm{~atm}(x)$, $150 \mathrm{~kg} / \mathrm{cm}^{2}(\bigcirc), 300 \mathrm{~kg} / \mathrm{cm}^{2}(\triangle), 450 \mathrm{~kg} / \mathrm{cm}^{2},(+)$, $600 \mathrm{~kg} / \mathrm{cm}^{2}(\nabla)$.

the behavior of the densified glasses of P $\alpha$ MS differs considerably from that of PS, namely, in the present case of $\mathrm{P} \alpha \mathrm{MS}$, the peak of $C_{p}$ becomes smaller and the transition temperature becomes lower with the increasing of glassforming pressure, whereas in the case of PS, $C_{p}$ vs. temperature relation for densified glasses is almost the same despite the difference of the pressure and the specific volume.

\section{Numerical results}

Numerical results are summarized in Table I. The values of $T_{\mathrm{g}}, V$ at $T_{\mathrm{g}}, \Delta C_{p}, \Delta \alpha$ and $\Delta \beta$ are those under atmospheric pressure. The value of $\left(\Delta T_{\mathrm{g}} / \Delta P\right)$ is the mean value between 1 atm and $150 \mathrm{~kg} / \mathrm{cm}^{2}$, To obtain $\Delta C_{p}$, we measured the specific heats of quenched $\mathrm{P} \alpha \mathrm{MS}$ twenty times with DSC and averaged.

Table I. Numerical results

\begin{tabular}{lll}
\hline$T_{\mathrm{g}}\left(1 \mathrm{~atm}, 1{ }^{\circ} \mathrm{C} / 3 \mathrm{~min}\right)$ & 166.5 & ${ }^{\circ} \mathrm{C}$ \\
$V$ at $T_{\mathrm{g}}$ & 0.9584 & $\mathrm{cc} / \mathrm{g}$ \\
$\Delta \alpha$ & $3.98 \times 10^{-4}$ & $\mathrm{~K}-1$ \\
$\Delta C_{p}$ & 0.076 & $\mathrm{cal} / \mathrm{g} \mathrm{K}$ \\
$\Delta \beta$ & $2.06 \times 10^{-5}$ & $\left(\mathrm{~kg} / \mathrm{cm}^{2}\right)^{-1}$ \\
$T V \alpha / \Delta C_{p}$ & 0.052 & $\mathrm{~K} /\left(\mathrm{kg} / \mathrm{cm}^{2}\right)$ \\
$\Delta \beta / \Delta \alpha$ & 0.052 & $\mathrm{~K} /\left(\mathrm{kg} / \mathrm{cm}^{2}\right)$ \\
$\left(\partial T_{\mathrm{g}} / \partial P\right)^{\mathrm{a}}$ & 0.039 & $\mathrm{~K} /\left(\mathrm{kg} / \mathrm{cm}^{2}\right)$ \\
\hline
\end{tabular}

a Mean value between $1-150\left(\mathrm{~kg} / \mathrm{cm}^{2}\right)$. The other values are those under $1 \mathrm{~atm}$.

\section{DISCUSSION}

The fact that the specific volumes at $30^{\circ} \mathrm{C}$ were not equal to each other, i.e., $\beta^{\prime}$ was not 
zero, show the invalidity of the concept of the iso-free volume at $T_{\mathrm{g}}$.

The pressure dependence of $T_{\mathrm{g}}$ is expressed in terms of $\beta^{\prime}$ by $^{3}$

$$
\left(\frac{\partial T_{\mathrm{g}}}{\partial P}\right)=\frac{\Delta \beta-\beta^{\prime}}{\Delta \alpha}
$$

The values of $T_{\mathrm{g}}$ calculated by this equation are plotted in Figure 2 with triangles. In the calculation the value of $\beta^{\prime}$ is taken from Figure $5 \mathrm{~b}$, and $\Delta \alpha$ and $\Delta \beta$ used are those under atmospheric pressure. The use of $\Delta \alpha$ and $\Delta \beta$ under atmospheric pressure caused no large error. The calculated values agree well with the experimental ones except that for $600 \mathrm{~kg} / \mathrm{cm}^{2}$.

If the criterion of iso-configrational entropy (iso- $S^{\mathrm{c}}$ ) or energy (iso- $U^{\mathrm{c}}$ ) is valid for $T_{\mathrm{g}}$ under elevated pressure, the heats of solution of the densified glasses should be constant and $(\partial H / \partial P)$ should be zero, which is almost equal to $\left(\partial U^{\mathrm{c}} /\right.$ $\partial P$ ) when $H$ is measured at the same temperature and pressure, because $U^{c}$ is defined as the internal energy frozen in at $T_{\mathrm{g}}$ and remains constant in the glassy state. ${ }^{3}$ The results shown in Figures 6 and $7 \mathrm{a}$ show that these predictions are not established. However, if we extrapolate the values $(\partial$ of $H / \partial P)$ to $P=0$, they become nearly zero, that is, $(-0.5 \pm 1.7) \times 10^{-3} \mathrm{cal} /$ $\mathrm{g}\left(\mathrm{kg} / \mathrm{cm}^{2}\right)$. Thus, it can be said that, below the pressure of $25-50 \mathrm{~kg} / \mathrm{cm}^{2}$, the iso-configurational entropy may be valid within the precision of the experiments.

According to Nose, ${ }^{3}$ the relation between $\left(\partial T_{\mathrm{g}} / \partial P\right)$ and $U^{\mathrm{c}}$ under low pressure is theoretically expressed as

$$
\left(\frac{\partial T_{\mathrm{g}}}{\partial P}\right)=\frac{T V \Delta \alpha}{\Delta C_{p}-\left(\frac{\partial U^{\mathrm{c}}}{\partial T_{\mathrm{g}}}\right)}
$$

The alternative expression of the above equation is

$$
\left(\frac{\partial T_{\mathrm{g}}}{\partial P}\right)=\frac{T V \Delta \alpha+\left(\frac{\partial U^{\mathrm{c}}}{\partial P}\right)}{\Delta C_{p}}
$$

The values of $T_{\mathrm{g}}$ calculated by eq 4 using experimental values of $\Delta \alpha, \Delta C_{p}$ and $\left(\partial U^{\mathrm{c}} / \partial P\right) \cong$ $(\partial \Delta H / \partial P)$ from Figure $7 \mathrm{~b}$ are plotted in Figure 2 with solid squares. The validity of eq 4 is also confirmed under the pressure range below
$450 \mathrm{~kg} / \mathrm{cm}^{2}$.

The discrepancy of $T_{\mathrm{g}}$ between the experimental and the calculated values in Figure 2 is not clear in the present stage. It is difficult to believe that $T_{\mathrm{g}}$ has the maximum value against pressure, because the mobility of the segments may become smaller and smaller with the increase of pressure. If $T_{\mathrm{g}}$ determined by the dilatometry of the glass formed under $600 \mathrm{~kg} /$ $\mathrm{cm}^{2}$ is true, there should be some reason for the abnormal decrease of the enthalpy and the specific volume of this glass. Supposing the crystallization, we can explain the decrease, but not the behavior of the specific heat. It is shown by the measurements of $[\eta]$ before and after the glassification that the possibility of degradation can be neglected. Further investigation is necessary to make clear this discrepancy.

Next, for the slowly cooled glasses, we derived the following relation for $\Delta H$ observed in Figure 6 in a previous paper and have shown its agreement with the experiments. ${ }^{2}$

$$
\Delta H=\Delta C_{p} \Delta T_{\mathrm{g}}
$$

where $\Delta C_{p}$ is the difference of specific heats between the liquid and glassy states and $\Delta T_{\mathrm{g}}$ is the difference of the glass transition temperatures due to the different glass-forming conditions. In the present study $\Delta C_{p}$ calculated by the above equation, that is to say, the observed slope in Figure 6 is $0.079 \mathrm{cal} \mathrm{g}^{-1} \mathrm{~K}^{-1}$ and $\Delta C_{p}$ from DSC measurement is $0.076 \mathrm{cal} \mathrm{g}^{-1} \mathrm{~K}^{-1}$. The derivation of eq 5 is based on the fact that the specific heats of different glasses are equal to each other.

Similarly, on the basis of the fact that $(\partial V /$ $\partial T)_{p}$ is equal for glasses with different histories, we can derive the increase of specific volume $\Delta V$ with the increase of $T_{\mathrm{g}}$ of the slowly cooled glass as follows:

$$
\begin{aligned}
\Delta V & =\int_{T_{\mathrm{g} 2}}^{T_{\mathrm{g} 1}}\left(\frac{\partial V}{\partial T}\right)^{1} d T-\int_{T_{\mathrm{g} 2}}^{T_{\mathrm{g} 1}}\left(\frac{\partial V}{\partial T}\right)^{\mathrm{g}} d T \\
& =\int_{T_{\mathrm{g} 2}}^{T_{\mathrm{g} 1}} \Delta\left(\frac{\partial V}{\partial T}\right) d T=\Delta\left(\frac{\partial V}{\partial T}\right)\left(T_{\mathrm{g} 1}-T_{\mathrm{g} 2}\right) \\
& =V \Delta \alpha \Delta T_{\mathrm{g}}
\end{aligned}
$$

where the superscripts 1 and $g$ refer to the liquid and glassy states respectively. The cal- 
Thermodynamic Studies on Glass Transition and Glassy State of Polymers. III.

culated value of $\Delta \alpha$ with this equation and Figure 4 is $3.92 \times 10^{-4} \mathrm{~K}^{-1}$ and the observed one is $3.98 \times 10^{-4}$.

The fact that the heats of solution of the densified glasses decrease with the decrease of specific volumes (Figure 8) may indicated that the decrease of intersegmental energy due to the contraction of volume is not compensated by the increase of the intrasegmental energy due to the high freezing temperature. As is discussed in the preceding paper, the difference of the specific heats due to the intrasegmental interactions between the liquid and glassy states, $\Delta C_{p}{ }^{\text {intra }}$, can be calculated by ${ }^{2}$

at

$$
\begin{aligned}
\Delta C_{p}{ }^{\text {intra }} & =\left(\frac{U_{1}^{\mathrm{c}}-U_{2}^{\mathrm{c}}}{T_{\mathrm{g} 1}-T_{\mathrm{g} 2}}\right)_{V_{1}=V_{2}} \\
& \cong\left(\frac{H_{1}-H_{2}}{T_{\mathrm{g} 1}-T_{\mathrm{g} 2}}\right)_{V_{1}=V_{2}}
\end{aligned}
$$

$$
T=\frac{T_{\mathrm{g} 1}+T_{\mathrm{g} 2}}{2}
$$

where the subscripts 1 and 2 refer to the glasses of different histories having the same volume $V_{1}=V_{2}$.

The value of $\Delta C_{p}^{\text {intra }}$ of $\mathrm{P} \alpha \mathrm{MS}$ calculated according to eq 7 is $0.007 \pm 0.01 \mathrm{cal} \mathrm{g}^{-1} \mathrm{~K}^{-1}$ which is $9 \pm 13$ percent of $\Delta C_{p}$. In the case of PS, $\Delta C_{p}$ intra is about 55 percent of $\Delta C_{p}$. This difference between PS and P $\alpha$ MS may be caused by the methyl side group in $\mathrm{P} \alpha \mathrm{MS}$.
Finally we calculated the energy difference $E$ between trans and gauche positions with the use of the most simple isomer model such as expressed $b^{5}$

$$
\frac{\Delta C_{p}^{\text {intra }}}{R}=\left(\frac{E}{R T}\right)^{2} \frac{2 \exp (-E / R T)}{[1+2 \exp (-E / R T)]^{2}} .
$$

Using $\Delta C_{p}{ }^{\text {intra }}=0.007 \mathrm{cal} \mathrm{g}^{-1} \mathrm{~K}^{-1}=0.41 \mathrm{cal} / \mathrm{K}$ (mole of $\mathrm{C}-\mathrm{C}$ bond), we obtained two solutions of eq 8 , i.e., $E=0.81 \mathrm{kcal} / \mathrm{mol}$ or $E=5.1 \mathrm{kcal} /$ mol. Though there is insufficient reason to choose one from the other, the value of 0.81 $\mathrm{kcal} / \mathrm{mol}$ appears suitable if we compare it with the value of $2.2 \mathrm{kcal} / \mathrm{mol}$ for PS obtained in a previous paper and in view of the above discussion.

\section{REFERENCES}

1. S. Ichihara, A. Komatsu, Y. Tsujita, T. Nose, and T. Hata, Polymer J., 2, 530 (1971).

2. S. Ichihara, A. Komatsu, and T. Hata, Polymer J., 2, 642 (1971).

3. T. Nose, Polymer J., 2, 445 (1971); see also, T. Nose and T. Hata, "Proceedings of The 5th Congress on Rheology", University of Tokyo Press, Tokyo, 3, 215 (1970).

4. M. V. Volkenshtein and Yu. A. Sharonov, Vysokomol. Soedin., 3, 1739 (1963).

5. T. M. Birshtein and O. B. Ptitsyn, "Conformations of Macromolecules" Interscience, New York, N.Y., 1966, P 233. 